\title{
Fabricating eco-friendly nanocomposites of SiC with morphologically-different nano-carbonaceous phases
}

\author{
Candelario, Victor M. ; Moreno, Rodrigo; Guiberteau, Fernando ; Ortiz, Angel L.
}

Published in:

Journal of the European Ceramic Society

Link to article, DOI:

10.1016/j.jeurceramsoc.2018.04.046

Publication date:

2018

Document Version

Peer reviewed version

Link back to DTU Orbit

Citation (APA):

Candelario, V. M., Moreno, R., Guiberteau, F., \& Ortiz, A. L. (2018). Fabricating eco-friendly nanocomposites of $\mathrm{SiC}$ with morphologically-different nano-carbonaceous phases . Journal of the European Ceramic Society, 38(11), 3735-3741. https://doi.org/10.1016/j.jeurceramsoc.2018.04.046

\section{General rights}

Copyright and moral rights for the publications made accessible in the public portal are retained by the authors and/or other copyright owners and it is a condition of accessing publications that users recognise and abide by the legal requirements associated with these rights.

- Users may download and print one copy of any publication from the public portal for the purpose of private study or research.

- You may not further distribute the material or use it for any profit-making activity or commercial gain

- You may freely distribute the URL identifying the publication in the public portal 


\section{Accepted Manuscript}

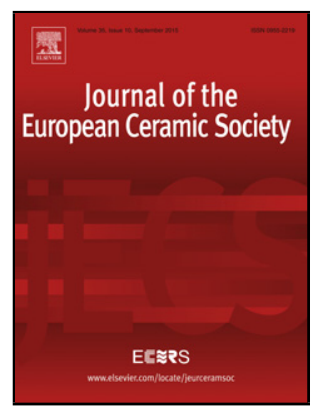

Title: Fabricating eco-friendly nanocomposites of $\mathrm{SiC}$ with morphologically-different nano-carbonaceous phases

Authors: Victor M. Candelario, Rodrigo Moreno, Fernando Guiberteau, Angel L. Ortiz

PII:

DOI:

Reference:

To appear in:

Received date:

Revised date:

Accepted date:
S0955-2219(18)30258-9 https://doi.org/10.1016/j.jeurceramsoc.2018.04.046 JECS 11856

Journal of the European Ceramic Society

$$
\begin{aligned}
& 17-4-2018 \\
& 21-4-2018
\end{aligned}
$$

Please cite this article as: Candelario VM, Moreno R, Guiberteau F, Ortiz AL, Fabricating eco-friendly nanocomposites of $\mathrm{SiC}$ with morphologically-different nano-carbonaceous phases, Journal of the European Ceramic Society (2010), https://doi.org/10.1016/j.jeurceramsoc.2018.04.046

This is a PDF file of an unedited manuscript that has been accepted for publication. As a service to our customers we are providing this early version of the manuscript. The manuscript will undergo copyediting, typesetting, and review of the resulting proof before it is published in its final form. Please note that during the production process errors may be discovered which could affect the content, and all legal disclaimers that apply to the journal pertain. 
Submitted to Journal of the European Ceramic Society, February 2018. Revised April 2018

\title{
Fabricating eco-friendly nanocomposites of SiC
}

\section{with morphologically-different nano-carbonaceous phases}

\author{
Victor M. Candelario ${ }^{\text {a,b }}$, Rodrigo Moreno ${ }^{c}$, Fernando Guiberteau ${ }^{\text {d }}$, Angel L. Ortiz ${ }^{\text {d,* }}$ \\ a LiqTech International AS, Industriparken 22C, 2750 Ballerup, Denmark. \\ ${ }^{b}$ Department of Energy Conversion and Storage, Technical University of Denmark, Ris $\varnothing$ \\ Campus, Frederiksborgvej 399, DK-4000 Roskilde, Denmark. \\ c Instituto de Cerámica y Vidrio, Consejo Superior de Investigaciones Científicas, \\ Madrid 28049, Spain. \\ d Departamento de Ingeniería Mecánica, Energética y de los Materiales, \\ Universidad de Extremadura, 06006 Badajoz, Spain.
}

\begin{abstract}
$\underline{\text { Abstract }}$
A route based on aqueous colloidal processing followed by liquid-phase assisted sparkplasma-sintering (SPS) is described for fabricating eco-friendly nanocomposites of SiC with nanocarbonaceous phases (nanotubes, nanoplatelets, or nanoparticles). To this end, the conditions optimizing the aqueous colloidal co-dispersion of $\mathrm{SiC}$ nanoparticles, $\mathrm{Y}_{3} \mathrm{Al}_{5} \mathrm{O}_{12}$ nanoparticles (acting as sintering additives), and carbon nanotubes (CNTs), graphene oxide (GO) nanoplatelets, or carbon black (CB) nanoparticles were first identified. Next, homogeneous powder mixtures were prepared by freeze-drying, and densified by liquid-phase assisted SPS, thus obtaining nanocomposites of SiC with CNTs, reduced GO (rGO) nanoplatelets, or pyrolized+graphitized CB $(\mathrm{p}+\mathrm{gCB})$ nanoparticles. It is also shown that these nanocomposites are dense and have a high hardness of 20 GPa regardless of the nano-carbonaceous phase chosen, but are markedly tougher with CNTs and rGO (i.e., with high aspect ratio nano-carbonaceous phases). Finally, arguments
\end{abstract}


are provided for the appropriate choice of nano-carbonaceous phases for engineering ceramic nanocomposites.

Keywords: SiC; aqueous colloidal processing; spark-plasma sintering; ceramic nanocomposites; nano-carbonaceous reinforcements.

* Corresponding author:
Angel L. Ortiz
Phone: +34 924289600 Ext: 86726
Fax: +34924289601
E-mail: alortiz@unex.es

\section{Introduction}

There is great interest today in the fabrication of composites based on ceramic matrices with nano-carbonaceous second phases dispersed in the microstructure (i.e., carbon nanotubes (CNTs), nanoplatelets of graphene (GNPs), graphene oxide (GO) or reduced graphene oxide (rGO), graphite nanoparticles (NG), carbon black (CB), etc.) [1-5]. This is because these composites have enhanced mechanical and functional properties relative to conventional ceramics [4,5]. This approach is being applied successfully to liquid-phase-sintered (LPS) SiC, which is a prominent non-oxide engineering ceramic for structural applications at both room and high temperatures [6-20]. Certainly, with respect to mechanical properties, in LPS SiC enhancements have been observed in (i) toughness with NG [21], GNPs [22], rGO [22], and CNTs [23,24], (ii) strength, contact-damage tolerance, and machinability with GNPs [22,25,26] and rGO [22,25], and (iii) wear resistance with NG [21], GNPs [27], and CNTs [23]. Regarding functional properties, in LPS SiC with GNPs, high thermal and electrical anisotropies have been observed [28,29], as well as prominent local transport properties [30]. Electrically functional cellular porous structures of LPS SiC with GNPs have also been fabricated, using robocasting as shaping technique [31]. Cellular hybrid materials of LPS SiC with certain types of aligned CNTs have also been developed 
having superhydrophobic and superoleophilic properties [32]. Thus, these examples show that it is possible to "reinforce" and functionalize LPS $\mathrm{SiC}$ with nano-carbonaceous second phases.

There are two critical aspects making the fabrication of the composites of ceramics with nano-carbonaceous second phases very problematical. One is to correctly disperse the nanocarbonaceous phases in the ceramic matrix [5] without damaging them, and the other is to prevent their degradation densification at high temperatures [5]. The problem is aggravated in the case of nanocomposites due to the additional difficulty of retaining nanograins during sintering, and becomes especially challenging if the condition of eco-friendly fabrication is imposed. This condition is met, for example, if the powder batches are first prepared by aqueous colloidal processing and next densified by spark-plasma sintering (SPS). The powder preparation stage is thus free from the safety and environmental concerns inherent in alcoholic slurries, and the densification stage is ultra-fast and energy efficient.

Accordingly, motivated by this challenge, we here explore the eco-friendly fabrication by aqueous colloidal processing plus liquid-phase assisted SPS of nanoceramics of SiC with variedmorphology nano-carbonaceous phases (i.e., nanotubes-CNTs, nanoplatelets-rGO, and nanoparticles-pyrolized+graphitized $\mathrm{CB}(\mathrm{p}+\mathrm{gCB}))$, and compare their mechanical properties (hardness and toughness).

\section{$\underline{\text { 2. Experimental procedure }}$}

The starting powders, obtained from commercial sources and used in their as-received condition, were: (i) $\beta$-SiC with a mean particle size of $45-55 \mathrm{~nm}$, (ii) $\mathrm{Y}_{3} \mathrm{Al}_{5} \mathrm{O}_{12}$ (YAG) with a mean particle size of $\sim 40 \mathrm{~nm}$, and (iii) multiwall CNTs with lengths of $0.5-2 \mu \mathrm{m}$, thicknesses of 10-20 nm and $\mathrm{OH}^{-}$functionalization (the three from Nanostructured and Amorphous Materials 
Inc., USA), as well as (iv) GO with lengths of $1-4 \mathrm{~nm}$ and thicknesses of $0.7-1.2 \mathrm{~nm}$ (from Nanoinnova Technologies, Spain), and (v) CB with a mean particle size of $\sim 32 \mathrm{~nm}$ (from Calblack N220, H.C. Starck, Germany). Nano-YAG was the sintering additive, and GO was chosen as starting material instead of $\mathrm{rGO}$ to facilitate the aqueous colloidal processing given that $\mathrm{GO}$ is then expected to transform into rGO during SPS. Three powder batches were prepared from these powders, as described next.

Firstly, dilute suspensions of nano-SiC, of nano-YAG, and of each of the nanocarbonaceous starting materials (i.e., CNTs, GO, or $\mathrm{CB}$ ) were individually prepared to a solid content of $0.1 \mathrm{~g} / \mathrm{l}$ in a solution of de-ionized water mixed with ethanol in a volume ratio of 9:1 together with $\mathrm{KCl} 10^{-2} \mathrm{M}$ as inert electrolyte, and, once equilibrated, their colloidal stability was studied by zeta potential measurements (Zetasizer Nano-ZS, Malvern, UK) as a function of $\mathrm{pH}$ and deflocculant content (this latter done, as usual, at natural $\mathrm{pH}$ to allow free adsorption of the polyelectrolyte introduced to shift down the isoelectric point). The $\mathrm{pH}$ was adjusted in the acidicbasic range using $10^{-1} \mathrm{M} \mathrm{HCl}$ or $\mathrm{KOH}$ solutions, respectively. Commercially available polyelectrolytes were used as deflocculants, in particular, PKV (Produkt KV5088, ZschimmerSchwarz, Germany) for nano-SiC and PAA (Duramax ${ }^{\mathrm{TM}}$ D-3005, Rohm \& Haas, USA) for nanoYAG and CB. PKV is a synthetic anionic polyelectrolyte with unknown composition that has demonstrated its suitability for the dispersion of non-oxide ceramics (including carbides [24,3338]), whereas PAA is an ammonium salt of polyacrylic acid that is known to be effective for oxide ceramics and metals [24,33-39]. Neither CNTs nor GO need deflocculants due to their surface functionalization. Secondly, multi-component suspensions with a total solids content of 5 vol.\% were formulated with composition of 86.24 vol.\% nano-SiC, 6.76 vol.\% nano-YAG, and 7 vol.\% nano-carbonaceous phase. The suspensions were prepared under continuous mechanical stirring 
with helices, using the following protocol of sequential addition. First, the $\mathrm{pH}$ of a mixture 9:1 by volume of de-ionized water and ethanol was adjusted to the desired value by dropwise addition of an aqueous solution of $25 \mathrm{wt} \%$ tetramethylammonium hydroxide (TMAH, Aldrich-Chemie, Germany). Next, the desired amount of either CNTs, GO, or CB was added, followed by initial sonication, incorporation of the PAA content required for their appropriate dispersion, and stabilization for $5 \mathrm{~min}$. Then, more PAA was added as needed to disperse the YAG nanoparticles, followed by addition of the nano-YAG powder and intermediate sonication for $1 \mathrm{~min}$. Lastly, PKV was added as required to disperse the $\mathrm{SiC}$ nanoparticles, followed by addition of the nano-SiC powder and final sonication for different times to thus investigate its influence on the rheological behaviour of the suspension. The $\mathrm{pH}$ was maintained at the desired value throughout the entire process.

The rheological behaviour of the resulting suspensions was evaluated using a rheometer (Mars, Haake, Thermo, Germany) operated in controlled shear rate mode. The measuring system consisted of a double-cone and plate, with cone angle of $2^{\circ}$, provided with a solvent trap to avoid evaporation. The measurement cycle of the flow curves involved a linear stretch of shear rate increase from 0 to $1000 \mathrm{~s}^{-1}$ in $300 \mathrm{~s}$, then a plateau at $1000 \mathrm{~s}^{-1}$ for $60 \mathrm{~s}$, and lastly a linear decrease to zero shear rate also in $300 \mathrm{~s}$. The thixotropy/rheopexy was determined from the area of the flow curve's hysteresis loop, and the viscosity by direct reading at $1000 \mathrm{~s}^{-1}$ in the uploading stretch.

Well-dispersed suspensions of nano-SiC+nano-YAG+CNTs/GO/CB were then frozen within a rotatory evaporator (RV10 basic, IKA, Germany) immersed in a liquid- $\mathrm{N}_{2}$ bath and subsequently freeze-dried (Cryodos-50, Telstar, Spain) at $-50{ }^{\circ} \mathrm{C}$ and $0.3 \mathrm{mPa}$, after which the resulting powder mixtures were examined by scanning electron microscopy (SEM; Quanta 3D FEG, FEI, The Netherlands). Next, each of the three powder mixtures was densified by SPS (Dr. 
Sinter SPS-2050, Sumitomo Coal Mining Co., Japan), under the following conditions: atmosphere of dynamic vacuum (which is indeed slightly reducing), peak temperature of $1700{ }^{\circ} \mathrm{C}$, heating ramp of $100{ }^{\circ} \mathrm{C} \cdot \mathrm{min}^{-1}$, soaking time of $5 \mathrm{~min}$, and uniaxial pressure of $75 \mathrm{MPa}$. The resulting nanocomposites were characterized using SEM and Raman spectroscopy (Nicolet Almega XR, Thermo Scientific, UK). The Raman spectra of the as-received CNT, GO, and CB powders were also acquired, and compared with those of the corresponding nanocomposites to elucidate possible changes during SPS. The relative density of the nanocomposites was measured using the Archimedes method.

Lastly, the nanocomposites were characterized mechanically by Vickers indentation tests (MV-1, Matsuzawa, Japan) at $98 \mathrm{~N}$ load (ten separate indentations on each material) to thus determine their hardness and fracture toughness by standard procedures and formulae [40].

\section{Results and discussion}

The first step of the routine for the eco-friendly fabrication of these appealing ceramic nanocomposites is to optimize the aqueous colloidal co-dispersion of nano-SiC, nano-YAG, and either CNTs, GO, or CB, in the desired proportions. Fig. 1 shows the evolution of the zeta potential as a function of $\mathrm{pH}$ for the individual dilute suspensions of nano-SiC [33-35], nano-YAG [33-35], CNTs $[33,34]$, GO, and CB. It can be seen that nano-SiC and nano-YAG have their isoelectric points at $\mathrm{pH} \sim 5.3$ and 8.8 , respectively. It can also be seen that CNTs and GO have their surface negatively charged in the whole range of $\mathrm{pHs}$ investigated, and that their isoelectric point will occur at $\mathrm{pH}<2$. This is because CNTs are intentionally functionalized with hydroxyl surface groups, whereas GO has carboxylic acid, hydroxyl, epoxy, and carbonyl surface groups [41]. Thus, unlike $\mathrm{rGO}, \mathrm{GO}$ is hydrophilic and therefore preferable as starting material when preparing suspensions, inks, and pastes in aqueous media. Finally, it can also be seen that CB behaves as 
nano-SiC does because the nano-SiC surface is enriched with some amorphous carbon [33]. By imposing the co-dispersion condition (i.e., the same sign of surface charge for the three compounds being mixed with zeta potential of the order of $\sim \pm 20 \mathrm{mV}$ ) it is inferred that the nano-SiC+nanoYAG+CNTs/GO/CB suspensions have to be prepared at $\mathrm{pH} \sim 12$. To avoid these extreme conditions, anionic polyelectrolytes will then be selectively used to shift isoelectric points towards more acidic pHs, so that the zeta potential becomes in all cases sufficiently high at less aggressive $\mathrm{pH}$ value (i.e., 10 or lower) to prepare well-dispersed suspensions.

It was observed during the preparation of the individual dilute suspensions that those of CNTs and GO were very stable colloidally. On the contrary, the CB suspension was hardly dispersible at all, therefore requiring deflocculant to promote its dispersibility. Nano-SiC and nano-YAG have to be deflocculated too, the former because it is the major solid in the powder mixtures and the latter because it exhibits a low absolute value of zeta potential at $\mathrm{pH} 10$ (i.e., only $\sim 10 \mathrm{mV}$ ). Fig. 2 shows the evolution of the zeta potential as a function of deflocculant content for the individual dilute suspensions of nano-SiC [33,35], nano-YAG [33,35], and CB, at their natural $\mathrm{pH}$. It can be seen that, in principle, appropriate deflocculant contents would be $0.5-1 \mathrm{wt} . \% \mathrm{PKV}$ for nano-SiC, 0.5-1 wt.\% PAA for nano-YAG, and 4 wt.\% PAA for CB. However, when preparing concentrated suspensions of ceramic nanopowders it is in practice much more recommendable to add higher deflocculant contents to avoid that the greater interaction between the ceramic nanoparticles induces agglomeration, reason for which nano-SiC and nano-YAG will be deflocculated using 4 wt.\% PKV and 2 wt.\% PAA, respectively, as had already been done in earlier work [33-35].

With the information obtained from the dilute suspensions, multi-component concentrated suspensions were prepared at $\mathrm{pH} 10$ using the protocol of sequential addition described above, but 
with some sonication variations to avoid re-agglomeration of the nano-carbonaceous phase. Continuous sonication was always applied to the suspension with CNTs (non-deflocculated), for $1 \mathrm{~min}$ in the initial sonication stage. However, it was observed that the continuous sonication induced re-agglomeration in the suspensions with $\mathrm{GO}$ or $\mathrm{CB}$, and, consequently, pulsed sonication (power discharge $0.5 \mathrm{~s}$ and pause $0.5 \mathrm{~s}$ ) was applied instead. The time of the initial sonication stage was 1 min for the suspension with GO (non-deflocculated), but 2 min for the suspension with CB due to its greater proneness to agglomeration. Deflocculation of CB was done after its sonication because otherwise the deflocculant would have stabilized nanoparticle agglomerates rather than primary nanoparticles.

The optimum final sonication time (continuous or pulsed) was determined by rheological studies. In this context, Fig. 3 shows selected flow curves of the three multi-component concentrated suspensions prepared with different final sonication times. It can be seen that the sonication time conditioned the rheological behaviour, as also did the nano-carbonaceous phase despite its being a minor compound in the suspensions. This is quantitatively clear in Fig. 4, which shows the values of the corresponding hysteresis loops and viscosities. Specifically, it can be observed that the suspensions with CNTs or CB behave similarly, first exhibiting an undesirable shear-thickening rheological behaviour with high rheopexy up to a certain final sonication time and then the desirable shear-thinning rheological behaviour with low thixotropy. In addition, the two suspensions have a similar viscosity which decreases with increasing final sonication time. This is because both CNTs and CB eventually act as physical barriers against the aggregation of the ceramic nanoparticles $[33,34]$. The relevant quantitative differences are that the suspension with CNTs has lower rheopexy for the same final sonication time and exhibits a sooner shearthickening $\rightarrow$ shear thinning transition (although with similar thixotropy) than the suspension with 
CB. Thus, apparently it seems that it is easier to prepare suspensions of ceramic nanoparticles with functionalized CNTs of high aspect ratio than with deflocculated CB of equiaxed morphology. Nonetheless, this could simply be due to the application of pulsed sonication (CB) instead of continuous sonication (CNTs). The suspension with GO behaves somewhat differently to the suspensions with CNTs or CB. Specifically, it exhibits a shear-thinning rheological behaviour, with rheopexy for all final sonication times applied. Nonetheless, foreseeably the suspension with GO would have been slightly thixotropic, but likely more viscous, if finally sonicated for more than 4 min. Also, the suspension's viscosity increases with increasing final sonication time, which is the trend typically observed in suspensions of non-equiaxed nanoparticles (which is the case of GO). In any case, these rheological measurements suggest that GO acts less satisfactorily than CNTs and CB as physical barrier against the aggregation of the ceramic nanoparticles. Nonetheless, it is important to emphasize that despite the qualitative and/or quantitative differences in rheological behaviour, there are always specific sonication conditions resulting in suspensions with almost no rheopexy or thixotropy. Consequently, it is always possible to prepare concentrated suspensions where the nano-SiC, nano-YAG, and the nano-carbonaceous phase are well enough dispersed, without formation or destruction of structures.

In view of the above results, the suspensions with CNTs, GO, and CB sonicated for 5, 4, and $6 \mathrm{~min}$, respectively, which are those exhibiting the best rheological behaviour of each series, were freeze-dried and the resulting powder mixtures were examined by SEM. Fig. 5 shows representative SEM images of the three powder mixtures so-obtained, which confirm the good dispersion state achieved in all cases with the particular conditions of aqueous colloidal processing used. The most relevant is that the nano-carbonaceous phase is homogeneously distributed 
between the ceramic nanoparticles, which is essential for the successful fabrication of these nanocomposites.

The second step of the routine for the eco-friendly fabrication of these appealing ceramic nanocomposites is to consolidate the powder mixtures by liquid-phase assisted SPS up to complete densification minimizing the growth of the $\mathrm{SiC}$ nanoparticles. Earlier work on $\mathrm{SiC}$ nanoceramics and SiC/CNTs nanocomposites has demonstrated that the SPS conditions optimizing their densification, nanograin size, and mechanical properties are $1700{ }^{\circ} \mathrm{C}$ for 5 min under $75 \mathrm{MPa}$ [24]. Smoother SPS conditions resulted in incomplete densification, whereas more stringent SPS conditions led to marked nanograin growth together with CNT degradation and worsening of the hardness and toughness [24]. Consequently, these optimal SPS conditions will also be applied in the present study involving a broader set of varied-morphology nano-carbonaceous phases. Fig. 6 shows representative SEM images of the fracture surface of the three nanocomposites fabricated. It can be seen that they densified completely, and that their microstructure consists of a nanocarbonaceous phase homogeneously distributed among SiC nanograins in turn surrounded by a residual intergranular phase. Thus, as expected, densification occurred by liquid-phase assisted SPS thanks to the nano-YAG sintering additive. Table I lists the densification degrees and the average nanograin size of the three nanocomposites. It can be observed that the nanocomposites with CNTs, rGO (because GO reduced during SPS), and $\mathrm{p}+\mathrm{gCB}$ (because $\mathrm{CB}$ pyrolyzed and graphited during SPS) attained complete densification (i.e., > 99\%). In addition, the average size of the SiC nanograins is very similar in the three cases, well below $100 \mathrm{~nm}$. Comparatively, the average nanograin size is smaller (by $\sim 23-30 \%$ ) in the nanocomposites than in the refence nanoceramic without nano-carbonaceous phases [24]. This is because the nano-carbonaceous phases are located at nanograin boundaries thus hindering the stages of solution, diffusion, and 
reprecipitation during the liquid-phase assisted SPS, which consequently results in an inhibition of the nanograin growth.

Fig. 7 shows the Raman spectra of the as-received nano-carbonaceous powders and of the three nanoceramics fabricated by SPS. It can be seen that the as-received CNTs exhibit the typical Raman bands (i.e., the D, G, and 2D bands) expected. However, it is clear that CNTs have gained structural quality after SPS because the intensity ratios of the D to G bands and of the 2D to D bands registered in the nanocomposite decreased and increased, respectively, relative to the asreceived CNT powder [24]. The as-received GO powder also exhibits the sequence of Raman bands expected. However, in the Raman spectrum of the corresponding nanocomposite some of the high-wavelength bands disappeared, indicating that GO reduced in situ during SPS. Consequently, this is basically a $\mathrm{SiC} / \mathrm{rGO}$ nanocomposite. The observations mentioned for $\mathrm{GO}$ are somewhat extendable to $\mathrm{CB}$, which pyrolized and graphitized in situ during SPS resulting in a $\mathrm{SiC} / \mathrm{p}+\mathrm{gCB}$ nanocomposite. It can thus be concluded that it is feasible to use liquid-phase assisted SPS to fabricate nanocomposites of $\mathrm{SiC}$ with $\mathrm{CNTs}$, rGO, and $\mathrm{p}+\mathrm{gCB}$.

Table I also lists the values of hardness and fracture toughness of the nanocomposites fabricated. They have hardnesses as great as $\sim 20 \mathrm{GPa}$, being only slightly softer (by $\sim 8 \%$ ) than the reference nanoceramic. The hardness of the nanocomposites is thus essentially dictated by the hard SiC nanograins, with a minor contribution from the nano-carbonaceous phase. It can also be observed in Table I that the nanocomposites with nano-carbonaceous phases of high aspect ratio (i.e., CNTs and $\mathrm{rGO}$ ) are tougher (by $~ 30-40 \%$ ) than the other nanocomposite (with $\mathrm{p}+\mathrm{gCB}$ ) and the reference nanoceramic, which is due to the more hindered crack propagation. Importantly, in terms of mechanical properties, there seem to be no reasons to prefer CNTs over rGO to reinforce nanoceramics, but the lower viscosity of the colloidal suspensions with CNTs would justify their 
preferential choice. The viscosity considerations will be more important with increasing total solid loading in the colloidal suspensions, and critical if pieces are to be shaped from these suspensions by wet-shaping techniques. It can also be seen that the equiaxed nano-carbonaceous phase (i.e., $\mathrm{p}+\mathrm{gCB})$ is ineffective ( $9 \%$ or less) in toughening the $\mathrm{SiC}$ nanoceramics. The nanocomposites with $\mathrm{p}+\mathrm{gCB}$ may have, however, appeal for tribological applications requiring resistance to severe wear (as demonstrated for composites with graphitized nano-diamond [21]), but less than the other nanocomposites. Given that its aqueous colloidal processing is also more tedious, unless cost is a critical concern it is thus not advisable to choose $\mathrm{p}+\mathrm{gCB}$ (and most likely other alternative equiaxed nanoparticles as well) as nano-carbonaceous phases over CNTs or rGO.

\section{Conclusions}

A route based on aqueous colloidal processing plus liquid-phase assisted SPS has been used for fabricating eco-friendly nanocomposites of $\mathrm{SiC}$ with different nano-carbonaceous phases (nanotubes, nanoplatelets, or nanoparticles). Based on the experimental results and analyses, the following conclusions can be drawn:

1. It is possible to prepare well-dispersed concentrated suspensions of nano-SiC+nanoYAG+CNTs/GO/CB with appropriate rheological behaviour (i.e., little thixotropy or rheopexy, and adequate viscosity) by aqueous colloidal processing. The nanocarbonaceous phase affects notably the rheological behaviour of these suspensions, with CNTs and GO not requiring deflocculants and with $\mathrm{GO}$ and $\mathrm{CB}$ requiring smoother sonication conditions (i.e., pulsed sonication instead of continuous sonication). Advisable conditions for the preparation of all these suspensions are high pHs (i.e., 10), moderate deflocculant contents for both nano-SiC (i.e., 4 wt.\%) and nano-YAG (i.e., 2 wt.\%), and short or medium final sonication times (i.e., 4-6 min). 
2. Freeze-drying of the colloidally-optimal suspensions provides homogeneous powder mixtures of nano-SiC+nano-YAG+CNTs/GO/CB, with a uniform distribution of the nanocarbonaceous phase among the ceramic nanoparticles.

3. It is feasible to fabricate fully-dense nanocomposites of $\mathrm{SiC}$ with $\mathrm{CNTs} / \mathrm{rGO} / \mathrm{p}+\mathrm{gCB}$ by liquid-phase assisted SPS from the freeze-dried powders. Their microstructure consists of a nano-carbonaceous phase homogeneously distributed among $\mathrm{SiC}$ nanograins (well below $100 \mathrm{~nm}$ ), in turn surrounded by a residual intergranular phase. During SPS, CNTs improve their crystallinity, GO reduces, and CB pyrolizes and graphitizes. The resulting SiC nanoceramics are very hard (hardnesses as great as $\sim 20 \mathrm{GPa}$ ), and are much tougher if the nano-carbonaceous phase has a high aspect ratio (i.e., CNTs and rGO).

4. It is more advisable to fabricate nanocomposites of $\mathrm{SiC}$ with $\mathrm{CNTs}$ or rGO than with $\mathrm{p}+\mathrm{gCB}$ because their aqueous colloidal processing is simpler and their mechanical properties are superior. In addition, choosing CNTs as nano-carbonaceous phase is the most recommendable because their colloidal suspensions are the least viscous, and hence the powder mixtures have less risk of undergoing agglomeration.

Acknowledgements. This work was supported by the Ministerio de Economía y Competitividad (Government of Spain) and FEDER (i.e., ERDF) Funds under the Grants no MAT2016-76638-R and MAT2015-67586-C3-2-R. Financial support from the Junta de Extremadura under the Grant no GR15078, also co-financed with FEDER (i.e., ERDF) Funds, is gratefully acknowledged as well. Thanks are also due to Prof. Zhijian Shen at the University of Stockholm for the assistance provided with the SPS furnace. 


\section{References}

1. W.A. Curtin, B.W. Sheldon, CNT-reinforced ceramics and metals, Mater Today 7 [11] (2004) 44-49.

2. X. Wang, N.P. Padture, H. Tanaka, Contact-damage-resistant ceramic/single-wall carbon nanotubes and ceramic/graphite composites, Nat Mater 3[8] (2004) 539-544.

3. A.L. Vasiliev, R. Poyato, N.P. Padture, Single-wall carbon nanotubes at ceramic grain boundaries, Scripta Mater 56 [6] (2007) 461-463.

4. N.P. Padture, Multifunctional composites of ceramics and single-wall carbon nanotubes, Adv Mater 21 [17] (2009) 1767-1770.

5. E. Zapata-Solvas, D. Gómez-García, A. Domínguez-Rodríguez, Towards physical properties tailoring of carbon nanotubes-reinforced ceramic matrix composites, J Eur Ceram Soc 32 [12] (2012) 3001-3020.

6. N.P. Padture, In situ-toughened silicon carbide, J Am Ceram Soc 77 [2] (1994) 519-523.

7. N.P. Padture, B.R. Lawn, Toughness properties of a silicon carbide with in situ-induced heterogeneous grain structure, J Am Ceram Soc 77 [10] (1994) 2518-2522.

8. N.P. Padture, B.R. Lawn, Contact fatigue of a silicon carbide with a heterogeneous grain structure, J Am Ceram Soc 78 [6] (1995) 1431-1438.

9. R.P. Jensen, W.E. Luecke, N.P. Padture, S.M. Wiederhorn, High-temperature properties of liquid-phase-sintered $\alpha-S i C$, Mater Sci Eng A 282 [1-2] (2000) 109-114.

10. A.L. Ortiz, A. Muñoz-Bernabé, O. Borrero-López, A. Domínguez-Rodríguez, F. Guiberteau, N.P. Padture, Effect of sintering atmosphere on the mechanical properties of liquid-phasesintered SiC, J Eur Ceram Soc 24 [10-11] (2004) 3245-3249. 
11. O. Borrero-López, A.L. Ortiz, F. Guiberteau, N.P. Padture, Improved sliding-wear resistance in in situ-toughened silicon carbide, J Am Ceram Soc 88 [12] (2005) 3531-3534.

12. M. Castillo-Rodríguez, A. Muñoz, A. Domínguez-Rodríguez, Correlation between microstructure and creep behavior in liquid-phase-sintered $\alpha$-silicon carbide, J Am Ceram Soc 89 [3] (2006) 960-967.

13. M. Castillo-Rodríguez, A. Muñoz, A. Domínguez-Rodríguez, Effect of atmosphere and sintering time on the microstructure and mechanical properties at high temperatures of $\alpha$-SiC sintered with liquid phase $\mathrm{Y}_{2} \mathrm{O}_{3}-\mathrm{Al}_{2} \mathrm{O}_{3}$, J Eur Ceram Soc 26 [12] (2006) 2397-2405.

14. J.J. Meléndez-Martínez, M. Castillo-Rodríguez, A. Domínguez-Rodríguez, A.L. Ortiz, F. Guiberteau, Creep and microstructural evolution at high-temperature of liquid-phase-sintered silicon carbide, J Am Ceram Soc 90 [1] (2007) 163-169.

15. O. Borrero-López, A.L. Ortiz, F. Guiberteau, N.P. Padture, Sliding-wear-resistant liquidphase-sintered SiC processed using $\alpha$-SiC starting powders, J Am Ceram Soc 90 [2] (2007) $541-545$.

16. O. Borrero-López, A.L. Ortiz, F. Guiberteau, N.P. Padture, Effect of liquid-phase content on the contact mechanical properties of liquid-phase-sintered $\alpha-S i C, J$ Eur Ceram Soc 27 [6] (2007) 2521-2527.

17. F. Rodríguez-Rojas, O. Borrero-López, A.L. Ortiz, F. Guiberteau, Oxidation behavior of pressureless liquid-phase-sintered $\alpha-\mathrm{SiC}$ in ambient air at elevated temperatures, $\mathrm{J}$ Mat Res 23 [6] (2008) 1689-1700.

18. E. Sánchez-González, P. Miranda, F. Guiberteau, A. Pajares, Effect of microstructure on the mechanical properties of liquid-phase-sintered silicon carbide at pre-creep temperatures, J Eur Ceram Soc 31 [6] (2011) 1131-1139. 
19. E. Ciudad, O. Borrero-López, F. Rodríguez-Rojas, A.L. Ortiz, F. Guiberteau, Effect of intergranular phase chemistry on the sliding-wear resistance of pressureless liquid-phasesintered $\alpha-S i C$, J Eur Ceram Soc 32 [2] (2012) 511-516.

20. O. Borrero-López, A.L. Ortiz, E. Ciudad, F. Rodríguez-Rojas, F. Guiberteau, Microstructural evolution and contact mechanical properties of $\mathrm{SiC}$ ceramics prepared colloidally with low additive content, Ceram Int 38 [7] (2012) 5979-5986.

21. V.M. Candelario, O. Borrero-López, F. Guiberteau, R. Moreno, A.L. Ortiz, Sliding-wear resistance of liquid-phase-sintered $\mathrm{SiC}$ containing graphite nanodispersoids, J Eur Ceram Soc 34 [10] (2014) 2597-2602.

22. M. Belmonte, A. Nistal, P. Boutbien, B. Román-Manso, M.I. Osendi, P. Miranzo, Toughened and strengthened silicon carbide ceramics by adding graphene-based fillers, Scripta Mater 113 (2016) 127-130.

23. V.M. Candelario, R. Moreno, F. Guiberteau, A.L. Ortiz, Enhancing the sliding-wear resistance of SiC nanostructured ceramics by adding carbon nanotubes, J Eur Ceram Soc 36 [13] (2016) 3083-3089.

24. V.M. Candelario, R. Moreno, Z. Shen, F. Guiberteau, A.L. Ortiz, Liquid-phase assisted sparkplasma sintering of $\mathrm{SiC}$ nanoceramics and their nanocomposites with carbon nanotubes, J Eur Ceram Soc 37 [5] (2017) 1929-1936.

25. M. Belmonte, P. Miranzo, M.I. Osendi, Contact damage resistant SiC/graphene nanofiller composites, J Eur Ceram Soc 38 [1] (2018) 41-45.

26. B. Román-Manso, E. Sánchez-González, A.L. Ortiz, M. Belmonte, M.I. Osendi, P. Miranzo, Contact-mechanical properties at pre-creep temperatures of fine-grained graphene/SiC 
composites prepared in situ by spark-plasma sintering, J Eur Ceram Soc 34 [5] (2014) 14331438.

27. J. Llorente, B. Román-Manso, P. Miranzo, M. Belmonte, Tribological performance under dry sliding conditions of graphene/silicon carbide composites, J Eur Ceram Soc 36 [3] (2016) $429-435$.

28. B. Román-Manso, Y. Chevillotte, M.I. Osendi, M. Belmonte, P. Miranzo, Thermal conductivity of silicon carbide composites with highly oriented graphene nanoplatelets, J Eur Ceram Soc 36 [16] (2016) 3987-3993.

29. B. Román-Manso, E. Domingues, F.M. Figueiredo, M. Belmonte, P. Miranzo, Enhanced electrical conductivity of silicon carbide ceramics by addition of graphene nanoplatelets, J Eur Ceram Soc 35 [10] (2015) 2723-2731.

30. P. Miranzo, L. López-Mir, B. Román-Manso, M. Belmonte, M.I. Osendi, C. Ocal, Prominent local transport in silicon carbide composites containing in-situ synthesized three-dimensional graphene networks, J Eur Ceram Soc 36 [13] (2016) 3073-3081.

31. B. Román-Manso, F.M. Figueiredo, B. Achiaga, R. Barea, D. Pérez-Coll, A. Morelos-Gómez, M. Terrones, M.I. Osendi, M. Belmonte, P. Miranzo, Electrically functional 3D-architectured graphene/SiC composites, Carbon 100 (2016) 318-328.

32. B. Román-Manso, S.M. Vega-Díaz, A. Morelos-Gómez, M. Terrones, P. Miranzo, M. Belmonte, Aligned carbon nanotube/silicon carbide hybrid materials with high electrical conductivity, superhydrophobicity and superoleophilicity, Carbon 80 (2014) 120-126.

33. V.M. Candelario, R. Moreno, A.L. Ortiz, Carbon nanotubes prevent the coagulation at high shears of aqueous suspensions of equiaxed nanoparticles, J Eur Ceram Soc 34 [3] (2014) 555563. 
34. V.M. Candelario, R. Moreno, Z. Shen, A.L. Ortiz, Aqueous colloidal processing of nano-SiC and its nano- $\mathrm{Y}_{3} \mathrm{Al}_{5} \mathrm{O}_{12}$ liquid-phase sintering additives with carbon nanotubes, $\mathrm{J}$ Eur Ceram Soc 35 [13] (2015) 3363-3368.

35. V.M. Candelario, R. Moreno, R.I. Todd, A.L. Ortiz, Liquid-phase assisted flash sintering of SiC from powder mixtures prepared by aqueous colloidal processing, J Eur Ceram Soc 37 [2] (2017) 485-498.

36. V.M. Candelario, F. Guiberteau, R. Moreno, A.L. Ortiz, Aqueous colloidal processing of submicrometric SiC plus $\mathrm{Y}_{3} \mathrm{Al}_{5} \mathrm{O}_{12}$ with diamond nanoparticles, J Eur Ceram Soc 33 [13-14] (2013) 2473-2482.

37. F. Rodríguez-Rojas, R. Moreno, F. Guiberteau, A.L. Ortiz, Aqueous colloidal processing of near-net shape B ${ }_{4}$ C-Ni cermet compacts, J. Eur. Ceram. Soc. 36 [8] (2016) 1915-1921.

38. F. Rodríguez-Rojas, R. Moreno, F. Guiberteau, A.L. Ortiz, Near-net shape manufacture of $\mathrm{B}_{4} \mathrm{C}-\mathrm{Co}$ and $\mathrm{ZrC}$-Co composites by slip casting and pressureless sintering, J. Eur. Ceram. Soc. 37 [15] (2017) 4577-4584.

39. J. Cesarano III, I.A. Aksay, Processing of highly concentrated aqueous $\alpha$-alumina suspensions stabilized with polyelectrolytes, J Am Ceram Soc 71 [12] (1988) 1062-1067.

40. D.G. Green, An Introduction to the Mechanical Properties of Ceramics, Cambridge University Press, Cambridge, UK, 1998.

41. D.R. Dreyer, S. Park, C.W. Bielawski, R.S. Ruoff, The chemistry of graphene oxide, Chem Soc Rev 39 (2010) 228-240.

Table I. Microstructural features and mechanical properties of the nanocomposite of SiC with CNTs, rGO, or $\mathrm{p}+\mathrm{gCB}$, and also of the reference $\mathrm{SiC}$ nanoceramic [24]. Note that GO reduced, and CB pyrolyzed and graphitized, in situ during SPS. 
Microstructural features

Mechanical properties

\section{Reinforcement}

\begin{tabular}{ccccc} 
& $\begin{array}{c}\text { Densification } \\
(\boldsymbol{\%})\end{array}$ & $\begin{array}{c}\text { Grain size } \\
(\mathbf{n m})\end{array}$ & $\begin{array}{c}\text { Hardness } \\
(\mathbf{G P a})\end{array}$ & $\begin{array}{c}\text { Fracture toughness } \\
\left(\mathbf{M P a} \cdot \mathbf{m}^{\mathbf{1} \mathbf{2}}\right)\end{array}$ \\
\hline CNTs & 100 & $65 \pm 28$ & $19.9 \pm 0.6$ & $3.2 \pm 0.3$ \\
rGO & 99 & $67 \pm 23$ & $19.9 \pm 0.9$ & $3.3 \pm 0.3$ \\
$\mathrm{p}+\mathrm{gCB}$ & 99 & $63 \pm 19$ & $20.5 \pm 1.8$ & $2.5 \pm 0.4$ \\
none & 100 & $87 \pm 26$ & $21.7 \pm 0.7$ & $2.3 \pm 0.3$ \\
\hline
\end{tabular}

42.

\section{$\underline{\text { Figure Captions }}$}

Figure 1. Dependence on $\mathrm{pH}$ of the zeta potential for the individual dilute suspensions of nanoSiC [33-35], nano-YAG [33-35], CNTs [33,34], GO, and CB. Lines are to guide the eye.

Figure 2. Dependence on deflocculant content (PKV for nano-SiC and PAA for nano-YAG, and $\mathrm{CB})$ of the zeta potential for the individual dilute suspensions of nano-SiC $[33,35]$, nano-YAG $[33,35]$, and $\mathrm{CB}$ at their natural $\mathrm{pH}$. Lines are to guide the eye.

Figure 3. Selected flow curves of the concentrated suspensions of nano-SiC+nano-YAG with (A) CNTs [33,34], (B) GO, and (C) CB subjected to different sonication times. Sonication times below 2 min were unsuitable for the nano-SiC+nano-YAG+CNTs suspension. The arrows indicate the uploading and downloading stretches of the flow curves.

Figure 4. Dependence on sonication time of the (A) hysteresis loop and (B) viscosity for the concentrated suspensions of nano-SiC+nano-YAG+CNTs/GO/CB. Lines are to guide the eye. In (A), the regions of rheopexy and thixotropy are distinguished. 
Figure 5. Representative SEM micrographs of the powder mixtures obtained by freeze-drying the rheologically-optimal concentrated suspensions of nano-SiC+nano-YAG with (A) CNTs, (B) GO, and (C) CB. Arrows/circles mark nano-carbonaceous phase (confirmed by SEM observations with back-scattered electrons).

Figure 6. Representative SEM micrograph of the microstructure (fracture surface of the broken specimen) of the nanocomposite of $\mathrm{SiC}$ with (A) CNTs, (B) $\mathrm{GGO}$, and (C) p+gCB. Note that GO reduced, and CB pyrolyzed and graphitized, in situ during SPS. The inset shows a magnified region.

Figure 7. Raman spectra (A) of the as-received CNTs, GO, and CB powders and (B) of the nanocomposites of $\mathrm{SiC}$ with $\mathrm{CNTs}, \mathrm{rGO}$, or $\mathrm{p}+\mathrm{gCB}$. Note that $\mathrm{GO}$ reduced, and $\mathrm{CB}$ pyrolyzed and graphitized, in situ during SPS. D, G and 2D bands are indicated.

\section{$\underline{\text { Table caption }}$}




\section{Figure Captions}

Figure 1. Dependence on $\mathrm{pH}$ of the zeta potential for the individual dilute suspensions of nanoSiC [33-35], nano-YAG [33-35], CNTs [33,34], GO, and CB. Lines are to guide the eye.

Figure 2. Dependence on deflocculant content (PKV for nano-SiC and PAA for nano-YAG, and CB) of the zeta potential for the individual dilute suspensions of nano-SiC $[33,35]$, nano-YAG $[33,35]$, and $\mathrm{CB}$ at their natural $\mathrm{pH}$. Lines are to guide the eye.

Figure 3. Selected flow curves of the concentrated suspensions of nano-SiC+nano-YAG with (A) CNTs [33,34], (B) GO, and (C) CB subjected to different sonication times. Sonication times below 2 min were unsuitable for the nano-SiC+nano-YAG+CNTs suspension. The arrows indicate the uploading and downloading stretches of the flow curves.

Figure 4. Dependence on sonication time of the (A) hysteresis loop and (B) viscosity for the concentrated suspensions of nano-SiC+nano-YAG+CNTs/GO/CB. Lines are to guide the eye. In (A), the regions of rheopexy and thixotropy are distinguished.

Figure 5. Representative SEM micrographs of the powder mixtures obtained by freeze-drying the rheologically-optimal concentrated suspensions of nano-SiC+nano-YAG with (A) CNTs, (B) GO, and (C) CB. Arrows/circles mark nano-carbonaceous phase (confirmed by SEM observations with back-scattered electrons).

Figure 6. Representative SEM micrograph of the microstructure (fracture surface of the broken specimen) of the nanocomposite of $\mathrm{SiC}$ with (A) CNTs, (B) $\mathrm{GGO}$, and (C) p+gCB. Note that GO reduced, and CB pyrolyzed and graphitized, in situ during SPS. The inset shows a magnified region. 
Figure 7. Raman spectra (A) of the as-received CNTs, GO, and CB powders and (B) of the nanocomposites of $\mathrm{SiC}$ with $\mathrm{CNTs}$, $\mathrm{GGO}$, or $\mathrm{p}+\mathrm{gCB}$. Note that $\mathrm{GO}$ reduced, and $\mathrm{CB}$ pyrolyzed and graphitized, in situ during SPS. D, G and 2D bands are indicated.

\section{$\underline{\text { Table caption }}$}

Table I. Microstructural features and mechanical properties of the nanocomposite of SiC with CNTs, rGO, or $\mathrm{p}+\mathrm{gCB}$, and also of the reference $\mathrm{SiC}$ nanoceramic [24]. Note that GO reduced, and CB pyrolyzed and graphitized, in situ during SPS. 


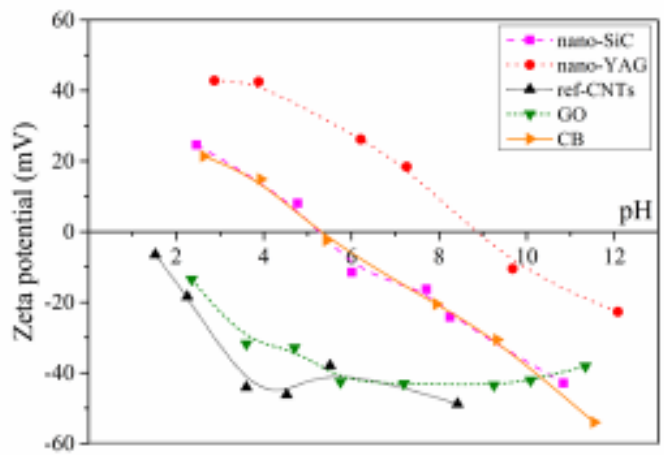

Cindelarin of of

Figure 1 


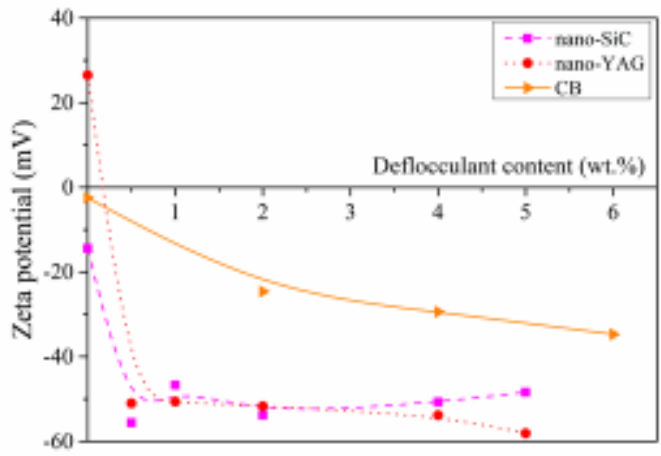

Candelario et of

Figure 2 

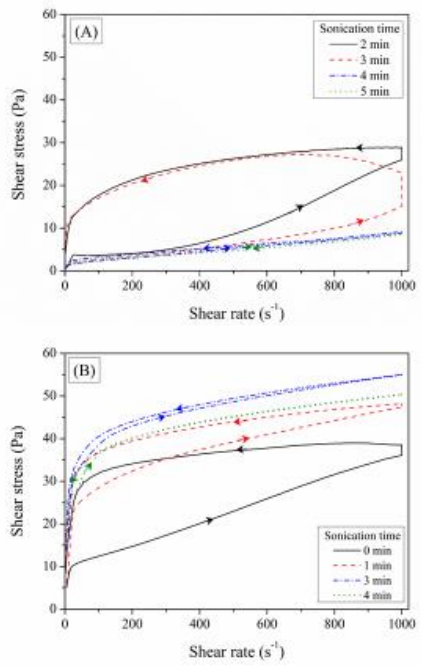

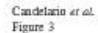

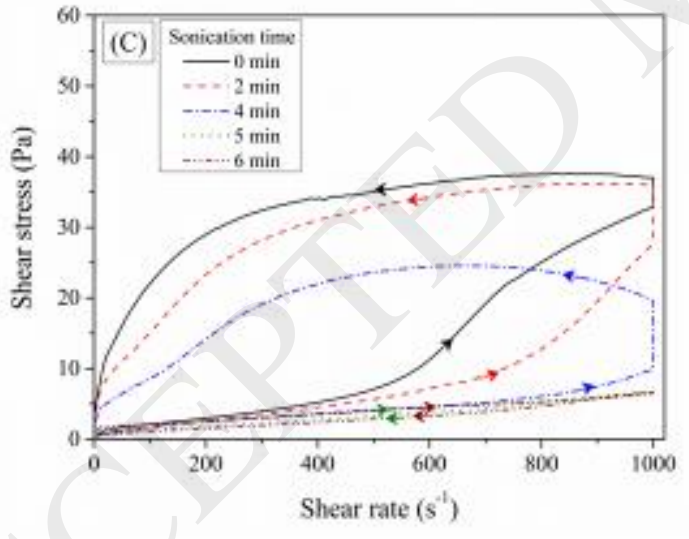

Candehrio et al

Figure 3 

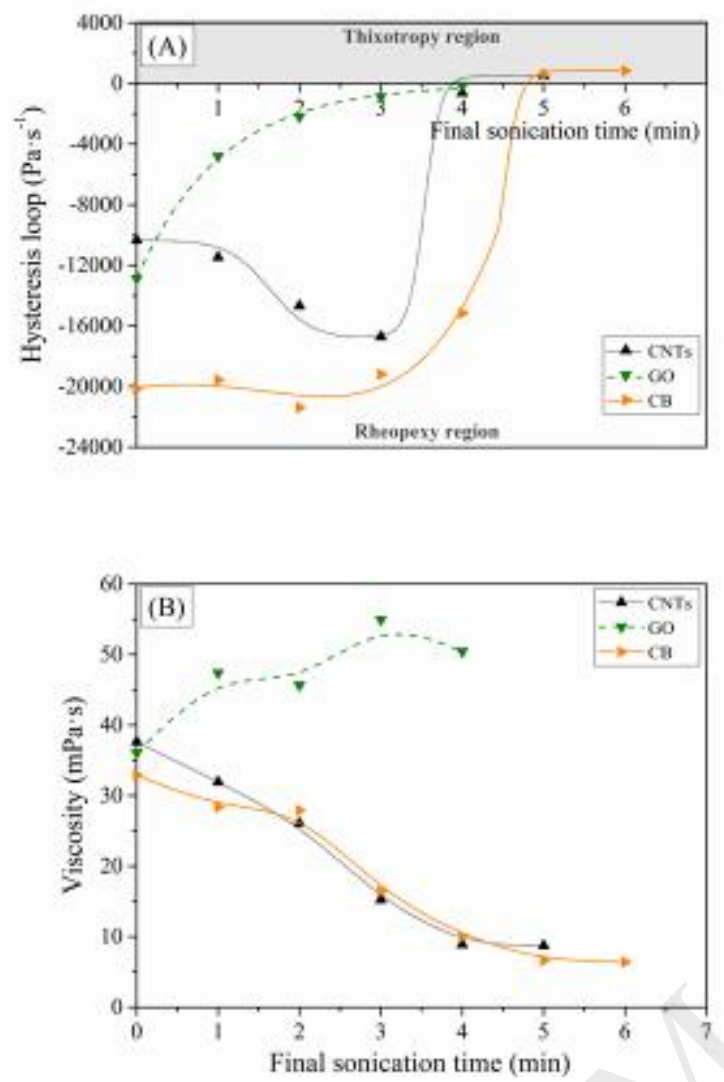

Candelario at of

Figure 4 

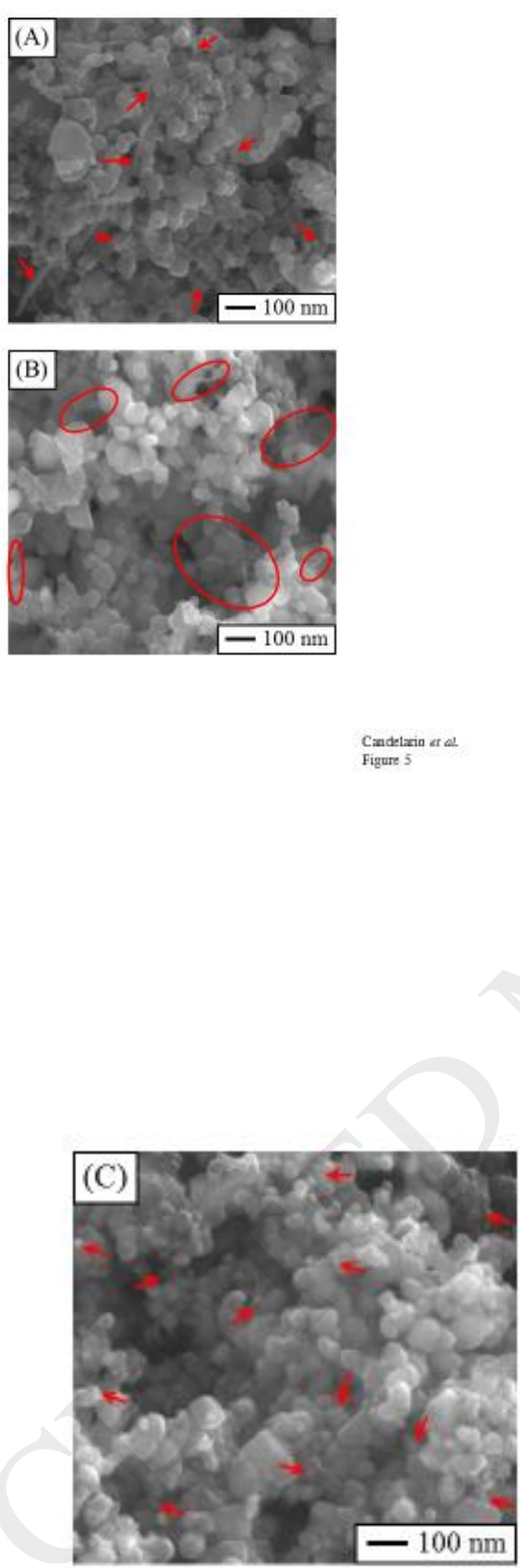

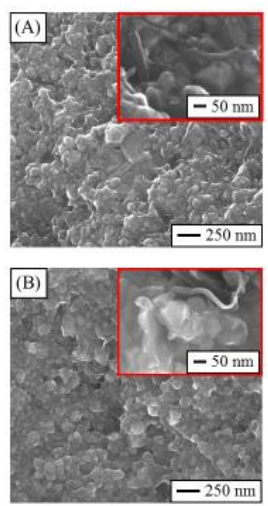

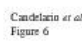

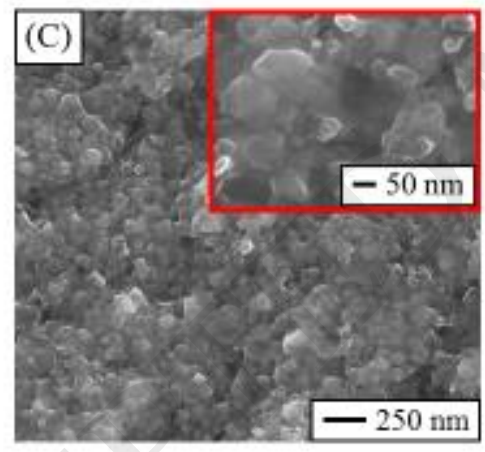

Candelario of of

Figure 6 

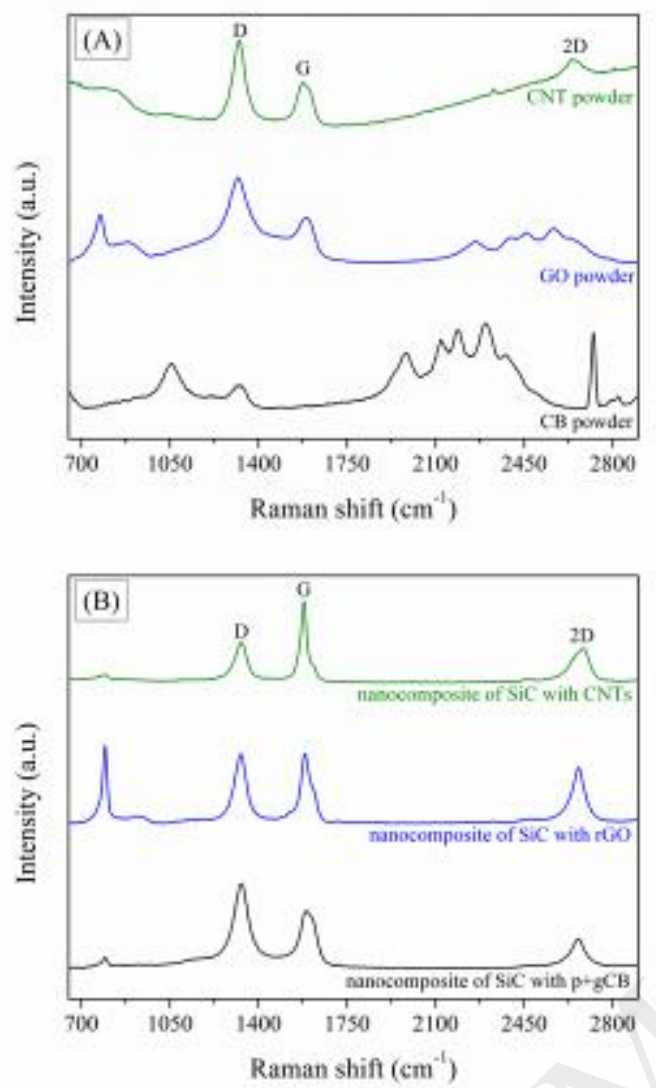

Candelario at of

Figure 7 